Fidei: Jurnal Teologi Sistematika dan Praktika, Vol. 4, No. 2, Des. 2021

Fidei: Jurnal Teologi Sistematika dan Praktika

Terakreditasi No: 85/M/KPT/2020 (Sinta 4)

e-ISSN: $2621-8135$

http://www.stt-tawangmangu.ac.id/e-journal/index.php/fidei

Vol. 4 No.2 (Des. 2021) hlm: 206-225

p-ISSN: 2621-8151

Diterbitkan Oleh: Sekolah Tinggi Teologi Tawangmangu

\title{
Membingkai Kemajemukan Melalui Pendidikan Agama Kristen di Indonesia
}

\author{
Shirley Lasut, Johny Hardori, Sadrakh Sugiono, Yada Putra Gratia, \\ Jannes Edward Sirait, Channel Eldad ${ }^{1)^{*}}$ \\ $\left.{ }^{1}\right)$ Sekolah Tinggi Teologi Bethel Indonesia, Indonesia \\ *) E-mail: shirleylasut9@ gmail.com
}

Diterima: 28 Agt. 2021 Direvisi: 13 Okt. 2021

Disetujui: 29 Nov. 2021

\begin{abstract}
Abstrak
Kemajemukan masyarakat Indonesia yang hidup di berbagai kepulauan memiliki sumber kekayaan alam dan kekayaan budaya yang besar. Namun disisi lain, pluralitas kultural ini memiliki potensi terjadinya disintegrasi atau perpecahan bangsa karena perbedaan pendapat dan pandangan hidup yang dianut. Hal ini membuktikan bahwa masyarakat Indonesia belum berhasil mengembangkan pendidikan yang menumbuhkan perilaku memberi apresiasi pada perbedaan-perbedaan budaya, agama maupun kebiasaan masyarakat suku. Fakta ini mendorong pendidikan Agama Kristen untuk segera melaksanakan peranannya dalam mempersatukan kemajemukan yang ada. Artikel ini bertujuan untuk membahas tentang pendekatan Pendidikan Agama Kristen dalam kehidupan masyarakat majemuk di Indonesia. Prosedur penelitian dari tulisan ini menggunakan metode kualitatif dan kajian kepustakaan khususnya mengenai pendekatan dan pengaturan pendidikan agama Kristen dalam kehidupan masyarakat majemuk. Hasil penelitian menyatakan bahwa guru Pendidikan Agama Kristen dan pengajar di gereja memasukkan pembahasan masyarakat majemuk dalam kurikulum atau ajaran dasar gereja yang selanjutnya dikembangkan dimensi pengetahuan, sosial, spiritual, dan komunal dari peserta didik dan jemaat.
\end{abstract}

Kata-Kata Kunci: Edukatif; Pluralitas; Masyarakat Majemuk; Pendidikan Agama Kristen

Copyright@2021; Fidei: Jurnal Teologi Sistematika dan Praktika, e-ISSN: 2621-8135, p-ISSN: 2621-8151| 206 


\section{Abstract}

The plurality of the Indonesian people who live in various islands has a large source of natural and cultural wealth. But on the other hand, this cultural plurality has the potential for disintegration or division of the nation due to differences in opinions and views of life held. This proves that the Indonesian people have not succeeded in developing education that fosters the attitude of giving appreciation to differences in culture, religion and customs of tribal communities. This fact awakens Christian religious education to immediately carry out its role in uniting the existing plurality. This article aims to discuss the approach to Christian Religious Education in people's lives in Indonesia. The research procedure of this paper uses qualitative methods and literature review, especially regarding the approach and regulation of Christian religious education in the life of a pluralistic society. The results of the study stated that Christian Religious Education teachers and church teachers included the discussion of plural society in the curriculum or the basic teachings of the church which further developed the knowledge, sosial, spiritual, and communal dimensions of the students and the congregation.

Keywords: Educational; Compound Society; Christian education; Plurality.

\section{Pendahuluan}

Kemajemukan Indonesia sudah diketahui oleh seluruh dunia. Fakta ini sudah melekat sejak berdirinya bangsa Indonesia pada 17 Agustus 1945. Berdasarkan Badan Pusat Statistik (BPS), jumlah suku di Indonesia yang tercatat pada tahun 2010 ada sekitar 1340an lebih suku di Indonesia dengan 633 suku besar. ${ }^{1}$ Sedangkan, dari sisi agama, melalui Putusan Mahkamah Konstitusi No.97/PUU-XIV/2016 (Putusan MK 97/2016), negara Indonesia mengakui 6 agama, yaitu Islam, Kristen, Katholik, Budha, Hindu, dan Konghucu. Tetapi, masih banyak agama-agama suku yang secara pengikut juga banyak dan masih tetap eksis sekalipun dalam dunia yang maju saat ini. Secara akademis disebut dengan berbagai istilah seperti agama tradisional kepercayaan, agama leluhur, ritual adat, agama leluhur, kepercayaan lokal dan agama lokal, dan agama primitif. ${ }^{2}$ Ini adalah fakta yang tidak bisa dihindarkan dari bangsa Indonesia dan seharusnya menjadi kehati-hatian juga untuk meramu perbedaan

\footnotetext{
${ }^{1}$ Badan Pusat Statistik, "Mengulik Data Suku Di Indonesia,” Badan Pusat Statistik, 2020.

${ }^{2}$ Sukirno Sukirno and Nur Adhim, "Implementasi Putusan Mahkamah Konstitusi No. 97/PUU-XIV/2016 Pada Masyarakat Adat Karuhun Urang Di Cigugur," Jurnal Penelitian Hukum De Jure 20, no. 1 (2020): 11, https://doi.org/10.30641/dejure.2020.v20.11-24.
} 
yang diuraikan di atas. Keberagaman budaya, kearifan lokal, suku, bahasa, agama, dan bahkan adat istiadat menjadi warisan yang perlu dijaga dan disyukuri. Terbentang sekitar 17.760 pulau dan lebih dari 1340 suku bangsa dengan bahasa yang berbeda-beda, serta memiliki sejarah budaya dan agama yang berbeda juga dari Sabang sampai Merauke. ${ }^{3}$ Setiap suku memiliki adat istiadat budaya suku yang didapati dari nenek moyang mereka.

Perbedaan-perbedaan yang telah dipaparkan di atas sebagai bukti kemajemukan masyarakat Indonesia karena berada dalam cakupan wilayah tinggal bersama-sama. Tanpa tinggal dan bersosialisasi bersama-sama, kemajemukan hanya data perbedaan suku diatas kertas tanpa terjadinya interaksi sosial. Karenanya, kemajemukan masyarakat terlihat dari dua variabel yaitu kemajemukan sosial dan kemajemukan budaya. Kemajemukan sosial berkaitan dengan status sosial yang ada di masyarakat seperti: lembaga, status, kelas, dan kekuasaan. Istilah "si kaya dan si miskin" dapat masuk dalam ranah sosial ini. Sedangkan kemajemukan budaya berkaitan dengan ras seseorang, bahasa, agama, kasta, ataupun wilayah. ${ }^{4}$

Masyarakat Indonesia menjadikan adat istiadat sebagai pegangan yang bersifat absolut melebihi kepercayaan kepada Allah. Namun kepercayaan juga membentuk worldview dari masyarakat yang mengajarkan untuk mencintai sesama manusia. Salah satu wujudnya dengan membangun hidup bersatu, tenggang rasa, kebersamaan, dan damai sejahtera dalam komunitas sukunya. Sedangkan disisi lain, perbedaan kepercayaan diantara mereka juga mengandung potensi terjadinya konflik dan perpecahan bangsa. Konflik itu terjadi karena masing-masing suku mempertahankan kepercayaannya dan adat istiadat mereka, sebagai kegiatan yang utama dan absolut kebenarannya. Sering terjadi kesalahpahaman antara ajaran masing-masing suku sehingga menimbulkan perdebatan yang berujung kekerasan. Agama atau kepercayaan suku hingga saat ini tetap menjadi pegangan yang sulit dilepaskan. Semangat kesukuan terkadang mengalahkan semangat nasionalisme.

Sebut saja permasalahan yang terjadi pada tahun 2020 di Nusa Tenggara Timur, di mana terjadi pertikaian antara warga desa Sandosi yang mengakibatkan lima orang tewas. Polisi menuturkan bahwa perebutan lahan

${ }^{3}$ Andreas Budi Setyobekti, Susanna Kathryn, and Suwondho Sumen, "Implementasi Nilai-Nilai Bhineka Tunggal Ika Dalam Membingkai Keberagaman Pejabat Gereja Bethel Indonesia Di DKI Jakarta," SOTIRIA (Jurnal Theologia Dan Pendidikan Agama Kristen) 4, no. 1 (2021): 1-10, https://doi.org/10.47166/sot.v4i1.29.

${ }^{4}$ Setyobekti, Kathryn, and Sumen. 
menjadi penyebab utamanya. ${ }^{5}$ Demikian yang terjadi antara etnis Lampung dengan Bali di Kabupaten Lampung Selatan dikarenakan masalah penghinaan SARA yang menyebabkan puluhan rumah dibakar dan puluhan unit mobil. ${ }^{6}$ Deretan-deretan permasalahan SARA menimbulkan kecemasan bagi masyarakat yang terlihat dari perilaku seperti adanya ketakutan untuk menetap di daerah konflik. ${ }^{7}$ Keadaan ini tentunya tidak lepas dari asupan pengetahuan yang dimiliki oleh orang-orang yang bertikai. Ketidakmampuan menyaring informasi yang dapat memecah belak, emosi yang tidak dewasa ketika mengalami ketersinggungan, hingga tenggang rasa dan rasa memiliki (sense of belonging) yang kuat antar sesama masyarakat Indonesia yang pudar. Dalam keadaan seperti ini, pendidikan penting untuk dikedepankan bagi seluruh masyarakat Indonesia. Pendidikan mampu memberikan pemikiran yang luas dalam memandang perbedaan, demikian juga pendidikan adalah wadah yang mudah untuk melakukan internalisasi nilai-nilai luhur Pancasila dan Bhineka Tunggal Ika secara komprehensif. Pada kesempatan inilah, Pendidikan Agama Kristen juga mesti muncul untuk melakukan pembinaan dan pengkorelasian nilai-nilai agama (khususnya Kristen) dengan kesatuan Bangsa.

Pendidikan Agama Kristen perlu memiliki strategi pendekatan yang tepat supaya dapat mengembangkan pendidikan agama Kristen pada setiap budaya suku secara kontekstual. ${ }^{8}$ Meskipun pada saat ini masih menghadapi masalah pandemi COVID-19, namun nilai-nilai Pendidikan Agama Kristen harus tetap diajarkan dan diterapkan dalam proses pendidikannya. ${ }^{9}$ Selain itu, Pendidikan agama Kristen menghadapi era disrupsi yang memerlukan adaptasi dari pendidik

\footnotetext{
5 Tim CNN Indonesia, "Bentrok Antar-Suku Pecah Di NTT, Warga Sebut Lima Tewas," CNN Indonesia, 2020, https://www.cnnindonesia.com/nasional/20200305175927-20480869/bentrok-antar-suku-pecah-di-ntt-warga-sebut-lima-tewas.

${ }^{6}$ Rahmatwati Prihastuty Latifa Faristin, Sugeng Hariyadi, "Akar Konflik Kerusuhan Antar Etnik Di Lampung Selatan," Journal of Sosial and Industrial Psychology 2, no. 1 (2013): $64-68$.

${ }^{7}$ Gernaida K R Pakpahan, “Analysis of Worring among Lecturers of Indonesian Bethel Theology on Covid-19," Medico-Legal Update 20, no. 4 (2020): 1330-37, https://doi.org/10.37506/mlu.v20i4.2014.

${ }^{8}$ Minggus, "Pembelajaran Kontekstual Di Masa Pandemi Untuk Mengembangkan Spiritualitas Anak," PASCA: Jurnal Teologi Dan Pendidikan Agama Kristen 17, no. 1 (2021): 82-97, https://doi.org/10.46494/psc.v17i1.126.

${ }^{9}$ Priskila Issak Benyamin, Ibnu Salman, and Frans Pantan, "Evaluasi Pembelajaran Daring Pendidikan Agama Kristen Di Masa Pandemi," Jurnal Teologi Berita Hidup 4, no. 1 (2021): 52-59.
} 
dan peserta didik. ${ }^{10}$ Langkah ini dirasa perlu untuk dilakukan para pendidik Pendidikan Agama Kristen supaya peserta didik, yakni anak-anak muda mengeluarkan potensi yang penuh dengan idealism serta memiliki kemampuan untuk melihat keberagaman sebagai kekayaan yang perlu disyukuri dan dilestarikan. ${ }^{11}$ Selain itu, guru PAK juga bertugas untuk mengungkapkan nilainilai atau pandangan hidup universal yang terdapat dalam masing-masing kepercayaan, sehingga melalui agama atau kepercayaan mereka masing-masing diharapkan dapat hidup dengan harmonis, memiliki toleransi tinggi, mampu berdampingan secara damai, saling menghormati, dan bekerjasama untuk menjaga kedaulatan bangsa dan menjadi sesama dalam kesulitan antar sesama manusia. $^{12}$

Pendidikan Agama Kristen jangan langsung dipahami sebagai pendidikan formal di sekolah dan menjadi bagian dalam penilaian yang hanya dilakukan atau dialami siswa yang masih aktif belajar. Pendidikan Agama Kristen pada dasarnya adalah tugas gereja dan dilakukan di gereja. ${ }^{13}$ Perjalanan waktu kemudian PAK identik dengan pendidikan formal di kelas-kelas. Namun pada prinsipnya, PAK tetaplah wadah dan tugas yang sangat penting di dalam dunia pendidikan pada masyarakat Kristen di Indonesia, dalam keluarga Kristen serta dalam lingkungan gereja. ${ }^{14}$ Karenanya, PAK dapat diterapkan secara bebas dalam kehidupan masyarakat gerejawi. Namun, management pembelajaran menjadi bagian sentral yang perlu diperhatikan agar proses penanaman nilai Kristiani dan kebangsaan Indonesia dapat berjalan dengan baik.

Berdasarkan fakta diatas, maka penelitian ini bertujuan untuk menemukan strategi Pendidikan Agama Kristen bagi siswa-siswi sekolah formal, masyarakat gerejawi dan Kristen di Indonesia dalam membingkai kesatuan, kebersamaan,

${ }^{10}$ Priskila Issak Benyamin, Ucok P Sinaga, and Febie Yolla Gracia, "Penggunaan 'Platform' Digital Pada Pembelajaran Pendidikan Agama Kristen Di Era Disrupsi," REGULA FIDEI: Jurnal Pendidikan Agama Kristen 6, no. 1 (2021): 60-68.

${ }^{11}$ Ibnu Salman, Priskila Benyamin, and Wartoni Wartoni, "Monitoring Model and Evaluation of ICT Utilization in The New Normal Era in Distance Learning in Madrasah," INCRE, no. January (2021): 1-8, https://doi.org/10.4108/eai.11-11-2020.2308302.

12 Jakson Sespa Toisuta, "Peran Dosen Mengatasi Permasalahan Pembelajaran Online Pada Masa Pandemi Covid-19," Fidei: Jurnal Teologi Sistematika Dan Praktika 4, no. 1 (2021): 23-42, https://doi.org/10.34081/fidei.v4i1.178.

${ }^{13}$ Robert R. Boehlke, Sejarah Perkembangan Pikiran Dan Praktek Pendidikan Agama Kristen (Jakarta: BPK Gunung Mulia, 2003); Frans Pantan, "Pendidikan Sebagai Tanggungjawab Gereja," in Bergereja Dalam Bingkai Kebangsaan, ed. Junifrius Gultom and Frans Pantan, 1st ed. (Jakarta: STT Bethel Indonesia, 2016), 24.

${ }^{14}$ Frans Pantan, "Ontologi Pendidikan Iman Kristen," in Education for Change, ed. Junifrius Gultom (Jakarta: Bethel Press, 2017). 
dan keharmonisan bangsa Indonesia agar mampu menempati ruang-ruang public dalam interaksi sosial. Artikel ini memberikan sumbangsih strategi Pendidikan Agama Kristen bagi pendidik, dosen teologi, pejabat gereja, dan masyarakat gerejawi dalam memandang kemajemukan sebagai karunia yang Allah berikan yang didalamnya setiap orang percaya mesti menghargai dan menjaganya.

\section{Metode Penelitian}

Pendekatan yang digunakan dalam penelitian ini adalah kualitatif etnografi. ${ }^{15}$ Penelitian ini hendak menggambarkan, menganalisa, dan menafsirkan unsur-unsur dari sebuah kelompok budaya, seperti pola perilaku, kepercayaan, dan bahasa yang berkembang dari waktu ke waktu. ${ }^{16}$ Teknik pengumpulan data penelitian ini menggunakan observasi, interview dan naratif inquiry. Data kemudian dianalisa dan dibuktikan keabsahannya melalui polyvocality serta verisimilitude. Hal ini dilakukan untuk mendapatkan hasil yang valid dan reliabel.

\section{Pembahasan dan Hasil}

\section{Pendidikan Agama Kristen: Bukan Hanya Pendidikan Formal}

Prinsip yang membedakan PAK dengan pendidikan formal lainnya adalah dasar yang digunakan untuk mengajar. Jika pendidikan formal mengedepankan pemahaman para pakar yang ahli dalam bidangnya, PAK mendasarkan ajarannya dari Alkitab sebagai otoritas tertinggi dalam mengajar Kristen dan dualitas pribadi Yesus Kristus. ${ }^{17}$ Proses pendidikan ini mengajarkan setiap orang Kristen mulai dari anak-anak hingga orang tua memahami keimanan Kristen dengan benar dan kuat. ${ }^{18}$ Hal ini menjadi penting untuk disoroti oleh PAK karena kehidupan dan teknologi yang semakin maju memudahkan siapa saja dan dimana saja mengakses pengajaran-pengajaran liar yang di permukaanya saja tidak sesuai dengan kebenaran Firman Tuhan, apalagi jika ditelusuri kepada

${ }^{15}$ Sonny Eli Zaluchu, "Strategi Penelitian Kualitatif Dan Kuantitatif Di Dalam Penelitian Agama," Evangelikal: Jurnal Teologi Injili Dan Pembinaan Warga Jemaat 4, no. 1 (2020): 28, https://doi.org/10.46445/ejti.v4i1.167.

${ }^{16}$ John W. Creswell, Research Design: Pendekatan Metode Kualitatif, Kuantitatif, Dan Campuran, Keempat (Yogyakarta: Pustaka Pelajar, 2016).

17 Sadrakh Sugiono and Johni Hardori, "Domain Desain Pembelajaran Inkarnatif," Diegesis: Jurnal Teologi 5, no. 2 (2020): 14-24, https://doi.org/10.46933/dgs.vol5i214-24.

${ }^{18}$ Neng Priyanti and Nabylla Sardy, "Epistemology Study: The Role of Christian Teachers Regarding Students Freedom in Learning," PASCA: Jurnal Teologi Dan Pendidikan Agama Kristen 17, no. 1 (May 2021): 43-54, https://doi.org/10.46494/psc.v17i1.122. 
kedalaman world view-nya. Belum lagi corak berpikir postmodern yang mengedepankan pluralisme dan relativisme. ${ }^{19}$

Corak berpikir, keadaan keterbukaan, dan kemajemukan yang ada di Indonesia pada masa postmodern ini menjadi peluang dan tugas PAK dalam mengimplementasikan kebenaran Alkitab dalam kehidupan orang Kristen dan komunitas masyarakat yang memiliki kebersamaan iman dalam Kristus dalam seluruh dimensi kehidupan mereka. Pada tingkatan tertentu, PAK dapat diarahkan sebagai cara dan media penginjilan karena didalamnya terdapat proses mematangkan orang Kristen secara spiritual dan praktis untuk menyebarkan Injil seturut dengan kapasitas dan kesempatan yang ada pada masyarakat yang majemuk. ${ }^{20}$ Dari pemikiran ini, dapat dikatakan bahwa PAK merupakan usaha untuk mempersiapkan manusia, yang dalam hal ini orang percaya kepada Yesus, untuk memahami, meresapi dan mengamalkan nilai-nilai dan ajaran agama itu sendiri. Karenanya, PAK berfungsi menumbuhkan iman orang percaya agar memiliki sikap dan perilaku seperti Yesus Kristus dan mengaplikasikan gaya hidup Kristus tersebut kepada komunitas masyarakat yang majemuk. ${ }^{21}$ Gaya hidup yang diajarkan Yesus, akan menjadi media penginjilan yang manjur untuk mencapai tujuan pendidikan agama Kristen, secara umum agar manusia memahami mana yang benar dan yang tidak benar, dan secara khusus, yaitu menjadikan semua bangsa murid Yesus.

Berkhof dan Til menegaskan bahwa pendidikan Kristen berbeda secara drastis dengan pendidikan sekuler. Perbedaan mendasar adalah bahwa PAK berdasarkan kebenaran Firman Tuhan, sedangkan pendidikan sekuler, berdasarkan intelektual seseorang. Hal ini penting untuk diperhatikan karena sesungguhnya, aspek keberhasilan pendidikan tidak hanya tentang pengetahuan (afektif), melainkan kehidupan akhlak (moralitas) dan integritas hidup sesuai dengan panggilan dan tuntutan moralitas Allah. Ada dasar-dasar pemahaman yang tidak bisa disamakan dengan PAK, seperti pendidikan sekuler yang mengajarkan bahwa manusia adalah hasil dari suatu proses evolusi yang terjadi secara kebetulan dan tidak memiliki makna kekekalan manapun. Itulah

${ }^{19}$ A M Hasiholan Tambunan and Andreas Budi Setyobekti, "Ekstraksi Pemahaman Cyprianus Tentang Extra Ecclesiam Nulla Salus Bagi Gereja Pentakosta Di Era Postmodern," KHARISMATA: Jurnal Teologi Pantekosta 4, no. 1 (2021): 28-42.

${ }^{20}$ Djoys Anneke Rantung, Pendidikan Agama Kristen Dalam Kehidupan Masyarakat Majemuk (Yogyakarta: Lintang Rasi Aksara Books, 2017).

${ }^{21}$ Anggrini Amelia Wongkar and Yuel Sumarno, "Agama Kristen Melalui Penerapan Strategi Pembelajaran Contextual Teaching and Learning," Edukasi: Jurnal Pendidikan Agama Kristen 11, no. 1 (2020): 1-7. 
sebabnya, pendidikan sekuler tidak membicarakan iman, moralitas dan panggilan Allah. ${ }^{22}$ Tentu pemahaman ini amat bertentangan, sebab manusia pada dasarnya diciptakan oleh Allah dalam gambar dan rupa-Nya. Hal ini sejalan dengan pernyataan Homrighausen dan Enklaar bahwa PAK berpangkal pada persekutuan umat Tuhan. Lebih lanjut Homrighausen dan Enklaar menyatakan bahwa dalam Perjanjian Lama, Pendidikan agama adalah tugas mulia sejak lama. Dimulai dari Adam dan Hawa hingga berlanjut kepada terpanggilnya Abraham menjadi nenek moyang umat Allah, Israel ketika dibawah tuntunan Musa, hingga ketika Yehuda kembali dari pembuangan di Babel. Karena itu, Allah menggunakan berbagai unsur untuk menjadi pendidik umat Allah, seperti para nabi, para imam, kaum bijaksana, dan keluarga. Sedangkan dalam Perjanjian Baru, guru Agung adalah Tuhan Yesus sendiri, yang memberi pengajaran tentang agama Kristen berdasarkan Alkitab dengan pengenalan akan Yesus Kristus. ${ }^{23}$ Tugas ini dilanjutkan oleh orang percaya dalam rangka membawa anak-anak mengenal pribadi Yesus dan kembali kepada rencana semula.

\section{Pendidikan Agama Kristen dalam Masyarakat Majemuk}

Pendidikan Agama Kristen dalam konteks multikultural dikembangkan oleh James A. Banks dengan penelitiannya mengenai multicultural education. Banks memulai pendidikan multikultural ini melalui gagasan bahwa semua murid (manusia) harus mengalami kesamaan atau kesederajatan pendidikan di sekolah-sekolah terlepas dari suku, etnis, ras, kelas sosial, agama, jenis kelamin, budaya, bahkan tingkat pengetahuan. Kultur disini tentunya bukan hanya berkaitan dengan budaya namun menyangkut juga dengan segala aspek kehidupan seseorang. Kehadiran PAK dalam masyarakat majemuk adalah implementasi dari teladan orang percaya, yaitu Yesus Kristus. Yesus tetap menghormati budaya dimana diri-Nya dilahirkan, tetapi juga mampu dan berani untuk menembus batas suku, agama, dan budaya. ${ }^{24}$ Lebih lanjut Banks memberikan dimensi yang mesti ada dalam pendidikan multikultural:

${ }^{22}$ Dede Novalis, Yuel Sumarno, and Josia Pantja Paruntung, "Penerapan Strategi Pembelajaran Kontekstual Dalam Upaya Meningkatkan Minat Belajar Pak,” Edukasi: Jurnal Pendidikan Agama Kristen 10, no. 1 (2019): 27-39. Mulia, 2013).

${ }^{23}$ EG Homrighausen and IH Enklaar, Pendidikan Agama Kristen (Jakarta: BPK Gunung

24 James Banks, Transforming the Multicultural Education of Teachers: Theory, Research and Practice, ed. M. Vavrus (New York, NY: Teachers College Press, 2002). 


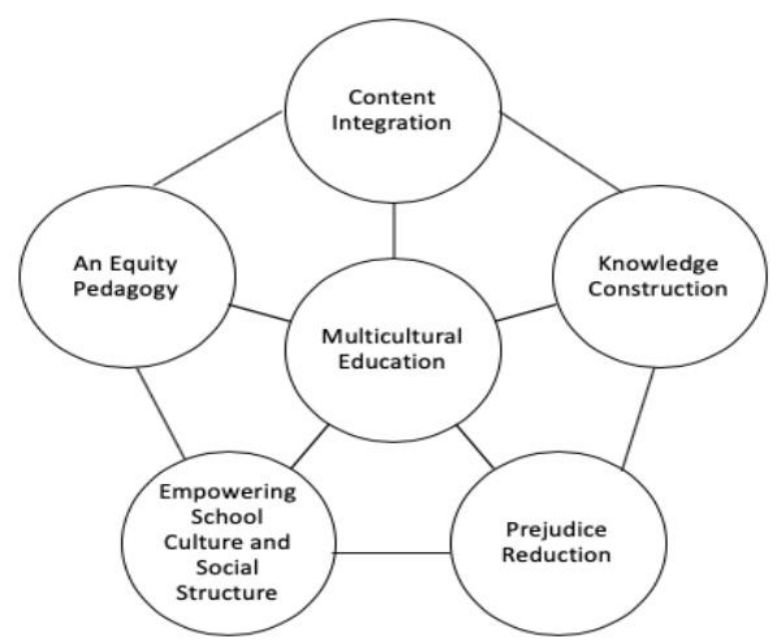

Gambar 1. Dimensi pendidikan Multikultural

Dimensi pertama adalah content Integration. Dimensi ini berhubungan dengan sejauh mana wawasan guru PAK dan pengajar di gerejawi memakai contoh-contoh dan konten dari berbagai budaya dan kelompok untuk mengilustrasikan kunci konsep, prinsip, generalisasi, dan teori dalam bidang atau disiplin ilmunya." Dimensi kedua, Empowering school culture and social structure. Merupakan proses restrukturisasi budaya dan organisasi sekolah sehingga siswa dari beragam kelompok ras, etnis, dan sosial akan mengalami kesetaraan pendidikan dan pemberdayaan budaya. Dimensi ketiga adalah Knowledge Construction. Proses konstruksi pengetahuan menjelaskan prosedur dimana pengetahuan sosial, perilaku, dan alam dimana manusia hidup menciptakan pengetahuan dan bagaimana budaya implisit asumsi, kerangka acuan, perspektif, dan bias dalam suatu disiplin mempengaruhi cara-cara itu pengetahuan dibangun di dalamnya. Dimensi keempat adalah Prejudice Reduction. Dimensi ini berfokus pada "karakteristik ras anak-anak" sikap dan strategi yang dapat digunakan untuk membantu siswa mengembangkan sikap yang lebih demokratis dan nilai-nilai. Dimensi kelima, pedagogi kesetaraan yaitu ketika guru mampu dan mesti memodifikasi sedemikian rupa bahan ajarnya untuk dapat memfasilitasi dan mengupayakan pencapaian akademik unggul bagi siswa dari beragam kelompok ras, budaya, dan kelas sosial. ${ }^{25}$ Pendidik perlu memiliki wawasan pendidikan, mengenal karakteristik peserta

${ }^{25}$ Yahya Han Erbaş, "Dimensions of Multicultural Education: Pedagogical Practices Knowledge of Graduate Students Towards Multicultural Education in Turkey," Mediterranean Journal of Educational Research 13, no. 27 (2019): 142-81, https://doi.org/10.29329/mjer.2019.185.7. 
didik dan tentunya memiliki kemampuan pedagogi yang diintegrasikan ke dalam teknologi. ${ }^{26}$

Dalam konteks Amerika, Banks secara masif memberikan dasar kemajemukan pendidikan Kristen yang berorientasi kepada kehidupan yang mampu bersahabat dengan perbedaan, apalagi dalam konteks Indonesia. Slogan "Unity in Diversity" seharusnya menjadi "Unity because diversity." Selaras dengan itu, Tafona memberikan beberapa alasan lain sehingga orang Kristen dalam pendidikan formal dan non-formal gereja didorong untuk melihat perlunya PAK dalam keberagaman agama dalam masyarakat majemuk, yaitu: (i) Konteks Indonesia adalah masyarakat multikultural; (ii) terdapat titik arsir antara PAK dan masyarakat multikultural, dimana pendidikan pasti akan menciptakan masyarakat sendiri yang multikultural; (iii) Mempelajari satu agama saja dalam masyarakat majemuk menjadi kegiatan yang tidak memadai dipandang dari hakikat pendidikan; (iv) Menguatkan wawasan multikultural pada masyarakat melalui guru-guru agama dan meningkatkan kemampuan masyarakat untuk mengelola berbagai keragaman atas dasar nilai-nilai kesetaraan antara manusia dan demokratis; v) Guru agama adalah tokoh kunci agar agama tidak menjadi penyakit yang membuat jurang antar kelompok masyarakat. $^{27}$

Dari paparan diatas, maka PAK memiliki dua peran yang perlu dilakukan dalam tataran formal dan gereja. Pertama, peran Edukatif. Tugas utama pendidik adalah memberikan pengajaran dan pendidikan yang memadai kepada peserta didiknya. Karenanya, peranan edukasi ini menjadi utama, penting dan sangat strategis dalam melahirkan sumber daya manusia yang memiliki moral dan akhlak yang baik. Peran pendidikan bukanlah hal yang baru dalam pelaksanaan PAK, tetapi kurikulum atau silabus yang terintegrasi kepada kehidupan yang menjadi sesama dalam kemajemukan adalah hal penting yang mesti dilakukan. Memasukkan kurikulum ini tidaklah sulit seharusnya, hanya memerlukan analisis dari para pengajar PAK untuk melakukan korelasi antara kepercayaan, ketaatan, dan komitmen iman Kristen dengan kehidupan berbangsa dan bernegara. Tanpa menyentuh atau terjebak dengan politik praktis, PAK dapat melakukan upaya untuk mendukung pemerintah dalam

${ }^{26}$ Salman, Benyamin, and Wartoni, "Monitoring Model and Evaluation of ICT Utilization in The New Normal Era in Distance Learning in Madrasah."

27 Talizaro Tafona'o, Pendidikan Agama Kristen Dalam Masyarakat Majemuk (Yogyakarta: Illumination Publishing, 2015). 
menyelenggarakan pendidikan yang berwawasan nasional serta mendukung program-program pengamalan Pancasila. ${ }^{28}$

Kedua, peran sosial. PAK memiliki peran dan kesempatan untuk memberikan contoh akan bagaimana menginternalisasi nilai-nilai kehidupan dan bermasyarakat dan, moral, dan etika dalam kehidupan bermasyarakat. Peran ini terintegrasi dengan pengajaran PAK bahwa untuk mengasihi sesama manusia, saling menghormati antara satu dengan yang lain, serta saling tolong-menolong tanpa membeda-bedakan golongan atau latar belakang. Hadinoto menegaskan bahwa PAK dalam bidang sosial dapat dilakukan dalam bentuk inkonvensional, misalnya: layanan masyarakat kota dan industri (PMKI), Yayasan bimbingan Kesejahteraan Sosial (YBKS), Yayasan diakonia modern di Jakarta, dan beberapa kelompok pelayanan sosial yang bekerja di samping gereja. ${ }^{29}$ Rantung lebih lanjut menyatakan bahwa peranan sosial ini dapat membangkitkan jiwa empati dan kepedulian dari siswa/i dan masyarakat gereja. Demikian dengan tindakan yang dilakukan oleh Gratia dkk yang berupaya untuk membangun model PAK untuk anak-anak korban kemiskinan. ${ }^{30}$

Ketiga, peran spiritual. Peranan spiritual ini adalah bagian utama dalam pendidikan Kristen, dan tentunya yang membedakan dengan pendidikan sekuler lainnya. ${ }^{31}$ Dalam konteks spiritual, PAK dapat memberikan pemahaman yang jelas mengenai konsekuensi hidup terkait dengan ketaatan seseorang terhadap janji dan juga kehancuran dan kematian kekal terkait kejahatan dan pelanggaran. ${ }^{32}$ Peran spiritual ini bertujuan untuk menjaga kemurniaan Iman Jemaat dan nara didik, serta mengarahkan kepada Karya keselamatan melalui pengenalan yang benar akan Allah, serta membangun generasi yang takut akan Tuhan dan percaya kepada janji-janji Tuhan. ${ }^{33}$

${ }^{28}$ Rantung, Pendidikan Agama Kristen Dalam Kehidupan Masyarakat Majemuk.

${ }^{29}$ N.K. Atmadja Hadinoto, Dialog Dan Edukasi: Keluarga Kristen Dalam Masyarakat Indonesia (Jakarta: BPK Gunung Mulia, 1990).

${ }^{30}$ Yada Putra Gratia et al., "Pengembangan Model Pendidikan Agama Kristen Bagi Anak Korban Kemiskinan," Jurnal Ecodunamika 3, no. 1 (2020): 1-11.

${ }^{31}$ Frans Pantan et al., "Resiliensi Spiritual Menghadapi Disruption Religious Value Di Masa Pandemi Covid-19 Pada Lembaga Keagamaan," KURIOS: Jurnal Teologi Dan Pendidikan Agama Kristen 7, no. 2 (2021).

32 Santy Sahartian, "Tugas Pemimpin Muda Kristen Masa Kini Sebagai Gembala Menurut 1 Timotius 4," Angelion: Jurnal Teologi Dan Pendidikan Kristen 1, no. 1 (2020); Yoel Betakore, "Menggapai Pengetahuan , Memperoleh Spiritualitas: Urgensi Dwi-Konsep Pengetahuan- Spiritualitas Dalam Pendidikan Agama Kristen," Edukatif: Jurnal Ilmu Pendidikan 3, no. 6 (2021): 3975-83.

${ }^{33}$ Rantung, Pendidikan Agama Kristen Dalam Kehidupan Masyarakat Majemuk. 


\section{Strategi Pendidikan Agama Kristen dalam Masyarakat Majemuk}

Perubahan pandangan manusia pada masa postmodern, menuntut para guru dan pengajar PAK lebih memperhatikan kebutuhan strategi pembelajaran mengenai materi, pandangan mengenai kesucian dan kekudusan, serta dampak teknologi yang sangat kuat mempengaruhi pola kehidupan masyarakat. ${ }^{34}$ Banyak orang yang mengalami keguguran iman karena tidak sanggup menghadapi perubahan-perubahan tersebut, baik yang tinggal di perkotaan maupun yang tinggal di tempat-tempat pedesaan terpencil. Kehadiran pendidikan agama Kristen sangat penting untuk membentuk akhlak dan moralitas agar masyarakat memiliki perilaku, nilai-nilai, dan pandangan hidup yang baik. Tantangan perubahan nilai yang yang dihadapi, yang sangat besar pengaruhnya dalam kehidupan kita adalah dunia komunikasi, nilai moral dan etika, serta kekerasan sosial. ${ }^{35}$ Banyak sekali orang yang menyalahgunakan alat komunikasi seluler, serta nilai-nilai kekudusan bukan lagi merupakan hal yang prinsip dalam kehidupan mereka, dan juga rasa kasih sayang di antara sesama menjadi kurang sehingga tidak heran banyak sekali kasus sadisme dan kekerasan yang terjadi di tengah-tengah masyarakat.

Isi pendidikan agama Kristen yang dapat diterapkan di tengah masyarakat majemuk yaitu sebagai berikut. Pertama, pengajaran iman Kristen. Tentu ini menjadi pembeda dengan pendidikan lainnya. Di sini, PAK bertugas membantu peserta didik dalam pemahaman doktrinal kehidupan bermasyarakat yang mengarah kepada tindakan praktis yang dapat dilakukan. Kedua, pengembangan spiritual: di sini PAK harus membantu peserta didik untuk mengembangkan kerohanian dan sikap serta perbuatan mereka, serta membimbing ke arah kedewasaan rohani. ${ }^{36}$ Ketiga, pembebasan yang diarahkan kepada kehidupan bermasyarakat peserta didik dalam menghayati gaya hidup kristiani dengan terlibat langsung di lingkungan masyarakat. Keempat, Relevansi yang diarahkan kepada kebutuhan-kebutuhan iman masa kini dengan segala corak berpikirnya. Hal ini supaya peserta didik dapat mengaplikasikannya secara konsisten meskipun terdapat tantangan dan keadaan tertentu.

${ }^{34}$ Sadrakh Sugiono, "Kualitas Guru Pendidikan Agama Kristen (PAK)," in Reaffirming Our Identity: Isu-Isu Terpilih Menjawab Perubahan Sekaligus Mempertahankan Identitas, ed. Junifrius Gultom and Frans Pantan (Jakarta: Bethel Press, 2014), 167-86.

${ }^{35}$ Frans Pantan et al., "Resiliensi Spiritual Menghadapi Disruption Religious Value Di Masa Pandemi Covid-19 Pada Lembaga Keagamaan," KURIOS (Jurnal Teologi Dan Pendidikan Agama Kristen) 7, no. 2 (2021).

${ }^{36}$ Erita Dewi Sirait and Sadrakh Sugiono, "Implementasi Pendidikan Karakter Terhadap Karakter Siswa Di Sekolah Menengah Kejuruan Bethel Petamburan” 11 (2020): 16-31. 
Kelima, kecintaan kepada firman Allah. PAK hendaknya membawa peserta didik kepada kecintaannya terhadap firman Allah, dan menjadikan Firman itu sebagai pedoman dalam kehidupan mereka. Peserta didik menjadi pelaku firman Tuhan sebagai wujud kecintaannya kepada firman Tuhan. Keenam, membaharui sikap dan perilaku. Pengajaran PAK haruslah dapat memperbaharui sikap dan perilaku orang-orang percaya dan mampu menjadikannya sebagai ciptaan baru (2 Kor. 5:17). Ketujuh, penemuan jati diri. PAK adalah merupakan pencarian jati diri sehingga dapat menemukan kebenaran Allah di dalam dirinya dan memberi tempat kepada Roh Kudus dalam pengembangan rohani setiap pribadi. Kedelapan, prinsip integrasi, di mana pun pendidikan agama Kristen dilaksanakan, strategi dan pengelolaannya dilakukan secara kontekstual, sehingga tidak menjauhi masyarakat tetapi justru mendekatkan mereka kepada kehidupan kekristenan. ${ }^{37}$

Ciri-ciri PAK dalam masyarakat majemuk adalah bersifat partisipasi, terbuka terhadap perubahan, berkesinambungan, terarah dan terencana, dan berorientasi kepada manusia. Melalui PAK, manusia dapat mengalami pembaharuan dalam pemahaman dan tindakannya, menghayati posisinya dalam masyarakat majemuk, pembentukan sikap dan perilakunya, serta pembentukan jati diri. Tindakan ini berlandaskan pengertian dan fakta bahwa kedewasaan rohani bukanlah suatu hal yang mudah untuk dicapai dan terjadi dengan tiba-tiba melalui suatu ibadah kebangunan Rohani. Melainkan proses yang melibatkan pengajaran secara konsisten dan komprehensif, beribadah, berdoa, bersekutu, dan mempelajari Firman. Dengan adanya PAK dimungkinkan dan diharapkan dapat memajukan pemahaman orang Kristen tentang Allah dan mendorong mereka supaya dapat menerapkan value firman Tuhan dalam keseharian sebagai masyarakat yang takut akan Allah. ${ }^{38}$ Tujuan dari pendidikan agama Kristen adalah sebagai petunjuk untuk pertobatan, pemuridan, pertumbuhan rohani secara vertikal dan horizontal, dan pembentukan spiritual. Pendewasaan rohani harus terus meningkat menuju kepada kesempurnaan Kristus. ${ }^{39}$

${ }^{37}$ Sugiono and Hardori, "Domain Desain Pembelajaran Inkarnatif."

${ }^{38}$ Yonathan Wiryohadi, "Gereja Berbasis Visi \& Misi Kerajaan Allah,” in Reaffirming Our Identity: Isu-Isu Terpilih Menjawab Perubahan Sekaligus Mempertahankan Identitas, ed. Junifrius Gultom and Frans Pantan (Jakarta: Bethel Press, 2014); Gernaida K. R. Pakpahan, Frans Pantan, and Epafras Djohan Handojo, "Menuju Gereja Apostolik Transformatif," EPIGRAPHE: Jurnal Teologi Dan Pelayanan Kristiani 5, no. 1 (2021): 136-46.

${ }^{39}$ Roike Roudjer Kowal, "Implementasi Pendidikan Agama Kristen (PAK) Dalam Masyarakat Majemuk," RHEMA: Jurnal Teologi Biblika Dan Praktika 3, no. 2 (2017): 71-81, https://e-journal.stt-yestoya.ac.id/index.php/rhema/article/view/46. 
Setiap gereja menggunakan pendekatan dan metodologi masing-masing dalam menyelenggarakan pendidikan Kristiani. Beberapa ahli memetakan empat macam pendekatan Pendidikan Kristiani. Istilah Mapping menunjuk suatu peta kecenderungan pendekatan pendidikan Kristiani yang dipakai oleh gerejagereja. Pendekatan tersebut adalah: ${ }^{40}$

\section{Pendekatan instruksional (Religious Instruction)}

Pendekatan instruksional menunjuk pada instruksi (isi, metode pengajaran, peran fasilitator dan partisipan, ruangan) dan konteks belajar mengajar secara formal. Tujuan dari pendekatan ini adalah memampukan peserta didik untuk mendasarkan pada diri iman yang bersumber pada Alkitab dan menghubungkan iman dengan kehidupan. Pendekatan ini dimulai dengan kesadaran kritis (konsientisasi) akan keberadaan di ruang publik yang beragam dan perlunya dijaga agar tidak terjadi konflik horizontal yang tidak perlu. ${ }^{41}$ Tindakan nyata yang dapat dilakukan adalah instruksi lintas iman dengan melakukan dialog dari berbagai komunitas iman untuk menyelesaikan masalah yang ada di lapangan dari sudut pandang yang berbeda. Guru memiliki peranan untuk memberikan pemahaman bahwa perbedaan yang ada bukanlah sesuatu permusuhan, melainkan kekayaan yang harus diterima dengan terbuka.

\section{Pendekatan Perkembangan Spiritual (Spiritual Development)}

Pendekatan perkembangan spiritual merupakan pendekatan yang memanfaatkan pendekatan teori-teori psikologi perkembangan. Tujuan dari pendekatan perkembangan spiritual ini adalah membantu peserta didik atau partisipan untuk menumbuhkan kehidupan batin yang tercermin dengan hidup empati dan simpati dalam melihat kesulitan yang ada di masyarakat tanpa melihat identitas yang akan dibantu. Pendekatan ini mengarahkan kepada internalisasi nilai kekristenan mengasihi dan melakukan kebaikan bagi setiap orang tanpa memandang perbedaan. Guru mula-mula mengajarkan perikop Firman Tuhan tentang kebaikan-kebaikan yang dilakukan oleh tokoh Alkitab yang tidak memandang suku ataupun keyakinan. Misalkan kunjungan Nabi Elisa ke janda di Sarfat, kisah orang Samaria yang baik Hati, hingga Yesus

40 Jack L Syemor, Mapping Christian Education: Approaches to Congregational Learning (Nashville: Abingdon Press, 1997).

${ }^{41}$ A. B Susanto, "Pendididan Penyadaran Paulo Freire," At-Ta'dib 4, no. 1 (2020): 81100. 
Kristus yang mengunjungi perempuan Samaria di Sumur Yakub. ${ }^{42}$ Selanjutnya, peserta diarahkan untuk melihat dan menilai kehidupan sosial masyarakat agar menumbuhkan rasa simpati dan empatinya.

\section{Pendekatan Komunitas Iman (Faith Community)}

Komunitas ini adalah kumpulan orang-orang yang saling mengenal, memperhatikan, mengasihi, mendukung, menghibur, menguatkan, dan membantu (saling asah, asih, asuh). ${ }^{43}$ Tujuan dari pendekatan ini untuk menyuarakan dan mendirikan komunitas yang berpihak kepada perkembangan manusia yang utuh dan otentik. Manusia tidak lagi dilihat sebagai pribadi yang penuh kekurangan dan perbedaan, melainkan menjadi sesama dalam komunitas tanpa melihat tembok-tembok perbedaan. ${ }^{44}$ Dalam komunitas, setiap anggota dirangkul dengan keramahtamahan tanpa membedakan latar belakang suku, budaya, golongan, dan agama. Dalam konteks Pendidikan di ruang-ruang kelas, maka metode kelompok menjadi tindakan yang mesti dilakukan

\section{Pendekatan Transformasi Sosial (Social Transformation)}

Transformasi memiliki tujuan dari pendekatan transformasi sosial, yaitu membantu orang-orang dan komunitas-komunitas untuk mempromosikan (menekankan) kewarganegaraan yang setia dan perubahan sosial. ${ }^{45}$ Pendidik mengarahkan peserta didiknya untuk mulai memikirkan tindakan yang dapat dilakukan untuk terlibat dalam kehidupan sosial masyarakat yang pada proses dan tujuannya terjadi perubahan sosial. Tugas ini dapat dilakukan dengan pembelajaran berbasis penyelesaian masalah (problem solving). ${ }^{46}$ Peserta didik diarahkan untuk mampu berpikir kritis dalam menyikapi masalah-masalah yang

${ }^{42}$ Naftali Untung, "Kristus Dan Perempuan Samaria. Yohanes 41-42," in Misi Inklusif: Berjumpa Dengan Firman Dan Realitas Untuk Misi Yang Inklusif (Jakarta: STT Bethel Indonesia, 2017).

${ }^{43}$ Nency Dwi, Diana Sadrakh, and Aser Lasfeto, "Kompetensi Guru Pendidikan Agama Kristen Dalam Mengatasi Perilaku Belajar Bermasalah Siswa Kelas X Di Sekolah Menengah Atas Efata Tangerang Serpong," Edukasi: Jurnal Pendidikan Agama Kristen 10, no. 2 (2019): 40-49.

44 Jannes Eduard Sirait, "Persepsi Pendeta Jemaat Tentang Urgensi Manajemen Program Pelayanan Gereja Lokal,” PNEUMATIKOS: Jurnal Teologi Kependetaan 11, no. 2 (2021): 11831.

${ }^{45}$ Kurniawati Maryam, Pendidikan Kristiani Multikultural (Nusaloka, BSD, Tangerang: Bambo Brigde Press, 2014).

${ }^{46}$ Anastasia Runesi, Christian Yohanes, and Putri Maria Juliana, "Penerapan Strategi Pembelajaran Berbasis Masalah Dalam Pendidikan Agama Kristen Di Era Disrupsi," SIKIP: Jurnal Pendidikan Agama Kristen 2, no. 2 (2021): 73-83. 
terdapat dalam interaksi sosial. Selanjutnya mereka merumuskan solusi yang dapat diambil untuk menyelesaikan masalah tersebut. Dalam penyusunan solusi, penulis memberikan tiga bagian waktu yang harus dipikirkan oleh peserta didik, yaitu jangka pendek (solusi yang pada saat itu dapat dilakukan), jangka menengah (solusi yang dapat dilakukan pada waktu 5-10 tahun kedepan), dan jangka panjang (solusi yang dapat dilakukan pada masa depan dengan waktu yang tidak bisa ditentukan). Sedangkan secara subjek, solusi dapat dibuat dengan memperhatian siapa saja yang terlibat. Apakah pribadi yang mengambil tindakan, atau kelompok yang mengambil tindakan terhadap solusi yang disusun. Dua bagian ini akan mendorong peserta didik untuk memperbaiki cara pandang dan perilaku mereka dalam interaksi sosial.

\section{Simpulan}

Kemajemukan adalah realitas di Indonesia yang mesti dikelola dengan baik supaya dapat memberi dampak positif bagi kemajuan bangsa, dan bukanlah konflik horizontal yang merugikan masyarakat Indonesia sendiri. Karena itu, pendidikan Agama Kristen memiliki andil dalam membentuk sikap toleransi dan kebersamaan dalam perbedaan. Dari pemaparan diatas maka kita bisa mengetahui dan memahami berbagai strategi pendekatan dan pengaturan pendidikan agama Kristen khususnya di tengah-tengah masyarakat indonesia yang majemuk. Memang dalam pelaksanaannya, banyak tantangan yang dihadapi, khususnya di era sekarang ini, terjadi banyak perubahan-perubahan yang mempengaruhi pandangan dan pola pikir manusia secara umum terlebih masyarakat plural di Indonesia. Oleh karena itu, sebagai guru PAK dan gereja harus menjalankan hak dan kewajiban dalam melakukan pendekatan pendidikan agama Kristen kepada masyarakat yang majemuk sesuai dengan konsep yang benar, yaitu didalamnya bisa tercipta pribadi yang takut akan Tuhan, hidup toleransi, saling mengasihi antar sesama, dan tolong menolong tanpa memandang derajat atau latar belakang. Strategi yang dikerjakan dalam proses pendidikan agama Kristen harus menciptakan masyarakat yang majemuk ini untuk mengasihi Allah lebih dari segala sesuatu. Implikasi dari pemahaman ini adalah keterlibatan siswa dalam interaksi sosial di ruang-ruang publik, baik secara konfensional maupun virtual. Keterlibatan ini bukan mengarahkan kepada perdebatan melainkan keterbukaan menerima pandangan orang lain. 
222 Fidei: Jurnal Teologi Sistematika dan Praktika, Vol. 4, No. 2, Des. 2021

\section{Daftar Pustaka}

Banks, James. Transforming the Multicultural Education of Teachers: Theory, Research and Practice. Edited by M. Vavrus. New York, NY: Teachers College Press, 2002.

Benyamin, Priskila Issak, Ibnu Salman, and Frans Pantan. "Evaluasi Pembelajaran Daring Pendidikan Agama Kristen Di Masa Pandemi." Jurnal Teologi Berita Hidup 4, no. 1 (2021): 52-59.

Benyamin, Priskila Issak, Ucok P Sinaga, and Febie Yolla Gracia. "Penggunaan 'Platform' Digital Pada Pembelajaran Pendidikan Agama Kristen Di Era Disrupsi." REGULA FIDEI: Jurnal Pendidikan Agama Kristen 6, no. 1 (2021): 60-68.

Betakore, Yoel. "Menggapai Pengetahuan, Memperoleh Spiritualitas: Urgensi

Dwi-Konsep Pengetahuan- Spiritualitas Dalam Pendidikan Agama

Kristen." Edukatif: Jurnal Ilmu Pendidikan 3, no. 6 (2021): 3975-83.

Boehlke, Robert R. Sejarah Perkembangan Pikiran Dan Praktek Pendidikan Agama Kristen. Jakarta: BPK Gunung Mulia, 2003.

Creswell, John W. Research Design: Pendekatan Metode Kualitatif, Kuantitatif, Dan Campuran. Keempat. Yogyakarta: Pustaka Pelajar, 2016.

Dwi, Nency, Diana Sadrakh, and Aser Lasfeto. "Kompetensi Guru Pendidikan Agama Kristen Dalam Mengatasi Perilaku Belajar Bermasalah Siswa Kelas X Di Sekolah Menengah Atas Efata Tangerang Serpong." Edukasi: Jurnal Pendidikan Agama Kristen 10, no. 2 (2019): 40-49.

Erbaş, Yahya Han. "Dimensions of Multicultural Education: Pedagogical Practices Knowledge of Graduate Students Towards Multicultural Education in Turkey." Mediterranean Journal of Educational Research 13, no. 27 (2019): 142-81. https://doi.org/10.29329/mjer.2019.185.7.

Frans Pantan, Priskila Issak Benyamin, Johni Handori, Yuel Sumarno, and Sadrakh Sugiono. "Resiliensi Spiritual Menghadapi Disruption Religious Value Di Masa Pandemi Covid-19 Pada Lembaga Keagamaan." KURIOS (Jurnal Teologi Dan Pendidikan Agama Kristen) 7, no. 2 (2021).

Gratia, Yada Putra, Priskila Benyamin Issak, Yuel Sumarno, and Valentino Wariki. "Pengembangan Model Pendidikan Agama Kristen Bagi Anak Korban Kemiskinan.” Jurnal Ecodunamika 3, no. 1 (2020): 1-11.

Hadinoto, N.K. Atmadja. Dialog Dan Edukasi: Keluarga Kristen Dalam Masyarakat Indonesia. Jakarta: BPK Gunung Mulia, 1990.

Homrighausen, EG, and IH Enklaar. Pendidikan Agama Kristen. Jakarta: BPK Gunung Mulia, 2013. 
Kowal, Roike Roudjer. "Implementasi Pendidikan Agama Kristen (PAK) Dalam Masyarakat Majemuk.” RHEMA: Jurnal Teologi Biblika Dan Praktika 3, no. 2 (2017): 71-81. https://e-journal.sttyestoya.ac.id/index.php/rhema/article/view/46.

Latifa Faristin, Sugeng Hariyadi, Rahmatwati Prihastuty. "Akar Konflik Kerusuhan Antar Etnik Di Lampung Selatan." Journal of Sosial and Industrial Psychology 2, no. 1 (2013): 64-68.

Maryam, Kurniawati. Pendidikan Kristiani Multikultural. Nusaloka, BSD, Tangerang: Bambo Brigde Press, 2014.

Minggus. "Pembelajaran Kontekstual Di Masa Pandemi Untuk Mengembangkan Spiritualitas Anak." PASCA: Jurnal Teologi Dan Pendidikan Agama Kristen 17, no. 1 (2021): 82-97. https://doi.org/10.46494/psc.v17i1.126.

Novalis, Dede, Yuel Sumarno, and Josia Pantja Paruntung. "Penerapan Strategi

Pembelajaran Kontekstual Dalam Upaya Meningkatkan Minat Belajar Pak.” Edukasi: Jurnal Pendidikan Agama Kristen 10, no. 1 (2019): 27-39. Pakpahan, Gernaida K. R., Frans Pantan, and Epafras Djohan Handojo. "Menuju Gereja Apostolik Transformatif." EPIGRAPHE: Jurnal Teologi Dan Pelayanan Kristiani 5, no. 1 (2021): 136-46.

Pakpahan, Gernaida K R. "Analysis of Worring among Lecturers of Indonesian Bethel Theology on Covid-19." Medico-Legal Update 20, no. 4 (2020): 1330-37. https://doi.org/10.37506/mlu.v20i4.2014.

Pantan, Frans. "Ontologi Pendidikan Iman Kristen." In Education for Change, edited by Junifrius Gultom. Jakarta: Bethel Press, 2017.

_. "Pendidikan Sebagai Tanggungjawab Gereja." In Bergereja Dalam Bingkai Kebangsaan, edited by Junifrius Gultom and Frans Pantan, 1st ed., 24. Jakarta: STT Bethel Indonesia, 2016.

Pantan, Frans, Priskila Issak Benyamin, Johni Handori, Yuel Sumarno, and Sadrakh Sugiono. "Resiliensi Spiritual Menghadapi Disruption Religious Value Di Masa Pandemi Covid-19 Pada Lembaga Keagamaan." KURIOS: Jurnal Teologi Dan Pendidikan Agama Kristen 7, no. 2 (2021).

Priyanti, Neng, and Nabylla Sardy. "Epistemology Study: The Role of Christian Teachers Regarding Students Freedom in Learning." PASCA: Jurnal Teologi Dan Pendidikan Agama Kristen 17, no. 1 (May 2021): 43-54. https://doi.org/10.46494/psc.v17i1.122.

Rantung, Djoys Anneke. Pendidikan Agama Kristen Dalam Kehidupan Masyarakat Majemuk. Yogyakarta: Lintang Rasi Aksara Books, 2017. 
Runesi, Anastasia, Christian Yohanes, and Putri Maria Juliana. "Penerapan Strategi Pembelajaran Berbasis Masalah Dalam Pendidikan Agama Kristen Di Era Disrupsi." SIKIP: Jurnal Pendidikan Agama Kristen 2, no. 2 (2021): 73-83.

Sahartian, Santy. "Tugas Pemimpin Muda Kristen Masa Kini Sebagai Gembala Menurut 1 Timotius 4." Angelion: Jurnal Teologi Dan Pendidikan Kristen 1 , no. 1 (2020).

Salman, Ibnu, Priskila Benyamin, and Wartoni Wartoni. "Monitoring Model and Evaluation of ICT Utilization in The New Normal Era in Distance Learning in Madrasah." INCRE, no. January (2021): 1-8.

https://doi.org/10.4108/eai.11-11-2020.2308302.

Setyobekti, Andreas Budi, Susanna Kathryn, and Suwondho Sumen. "Implementasi Nilai-Nilai Bhineka Tunggal Ika Dalam Membingkai Keberagaman Pejabat Gereja Bethel Indonesia Di DKI Jakarta." SOTIRIA (Jurnal Theologia Dan Pendidikan Agama Kristen) 4, no. 1 (2021): 1-10. https://doi.org/10.47166/sot.v4i1.29.

Sirait, Erita Dewi, and Sadrakh Sugiono. "Implementasi Pendidikan Karakter Terhadap Karakter Siswa Di Sekolah Menengah Kejuruan Bethel Petamburan" 11 (2020): 16-31.

Sirait, Jannes Eduard. "Persepsi Pendeta Jemaat Tentang Urgensi Manajemen Program Pelayanan Gereja Lokal." PNEUMATIKOS: Jurnal Teologi Kependetaan 11, no. 2 (2021): 118-31.

Statistik, Badan Pusat. "Mengulik Data Suku Di Indonesia." Badan Pusat Statistik, 2020.

Sugiono, Sadrakh. "Kualitas Guru Pendidikan Agama Kristen (PAK)." In Reaffirming Our Identity: Isu-Isu Terpilih Menjawab Perubahan Sekaligus Mempertahankan Identitas, edited by Junifrius Gultom and Frans Pantan, 167-86. Jakarta: Bethel Press, 2014.

Sugiono, Sadrakh, and Johni Hardori. "Domain Desain Pembelajaran Inkarnatif." Diegesis: Jurnal Teologi 5, no. 2 (2020): 14-24. https://doi.org/10.46933/dgs.vol5i214-24.

Sukirno, Sukirno, and Nur Adhim. "Implementasi Putusan Mahkamah Konstitusi No. 97/PUU-XIV/2016 Pada Masyarakat Adat Karuhun Urang Di Cigugur." Jurnal Penelitian Hukum De Jure 20, no. 1 (2020): 11. https://doi.org/10.30641/dejure.2020.v20.11-24.

Susanto, A. B. "Pendididan Penyadaran Paulo Freire." At-Ta'dib 4, no. 1 (2020): $81-100$. 
Membingkai Kemajemukan... (Shirley, Johny, Sadrakh, Yada, Channel)

Syemor, Jack L. Mapping Christian Education: Approaches to Congregational Learning. Nashville: Abingdon Press, 1997.

Tafona'o, Talizaro. Pendidikan Agama Kristen Dalam Mayarakat Majemuk. Yogyakarta: Illumination Publishing, 2015.

Tambunan, A M Hasiholan, and Andreas Budi Setyobekti. "Ekstraksi Pemahaman Cyprianus Tentang Ext ra Ecclesiam Nulla Salus Bagi Gereja Pentakosta Di Era Postmodern." KHARISMATA: Jurnal Teologi Pantekosta 4, no. 1 (2021): 28-42.

Tim CNN Indonesia. "Bentrok Antar-Suku Pecah Di NTT, Warga Sebut Lima Tewas." CNN Indonesia, 2020.

https://www.cnnindonesia.com/nasional/20200305175927-20-

480869/bentrok-antar-suku-pecah-di-ntt-warga-sebut-lima-tewas.

Toisuta, Jakson Sespa. "Peran Dosen Mengatasi Permasalahan Pembelajaran

Online Pada Masa Pandemi Covid-19." Fidei: Jurnal Teologi Sistematika

Dan Praktika 4, no. 1 (2021): 23-42.

https://doi.org/10.34081/fidei.v4i1.178.

Untung, Naftali. "Kristus Dan Perempuan Samaria. Yohanes 41-42." In Misi Inklusif: Berjumpa Dengan Firman Dan Realitas Untuk Misi Yang Inklusif. Jakarta: STT Bethel Indonesia, 2017.

Wiryohadi, Yonathan. "Gereja Berbasis Visi \& Misi Kerajaan Allah." In Reaffirming Our Identity: Isu-Isu Terpilih Menjawab Perubahan Sekaligus Mempertahankan Identitas, edited by Junifrius Gultom and Frans Pantan. Jakarta: Bethel Press, 2014.

Wongkar, Anggrini Amelia, and Yuel Sumarno. "Agama Kristen Melalui Penerapan Strategi Pembelajaran Contextual Teaching and Learning." Edukasi: Jurnal Pendidikan Agama Kristen 11, no. 1 (2020): 1-7.

Zaluchu, Sonny Eli. "Strategi Penelitian Kualitatif Dan Kuantitatif Di Dalam Penelitian Agama." Evangelikal: Jurnal Teologi Injili Dan Pembinaan Warga Jemaat 4, no. 1 (2020): 28. https://doi.org/10.46445/ejti.v4i1.167. 